\title{
Endothelial nitric oxide synthase gene polymorphisms -786T $>C$ and 894G $>T$ in coronary artery bypass graft surgery patients
}

Georgia Ragia,' Eleftherios Nikolaidis, ${ }^{2}$ Anna Tavridou,' Kostas I. Arvanitidis,' Stavroula Kanoni, ${ }^{3}$ George V. Dedoussis, ${ }^{3}$ George Bougioukas ${ }^{2}$ and Vangelis G. Manolopoulos ${ }^{*}$

'Laboratory of Pharmacology, Medical School, Democritus University of Thrace, Alexandroupolis, Greece

${ }^{2}$ Cardiothoracic Surgery Clinic, Academic General Hospital of Alexandroupolis, Alexandroupolis, Thrace, Greece

${ }^{3}$ Department of Science in Dietetics and Nutrition, Harokopio University, Athens, Greece

*Correspondence to: Tel/Fax: +30 2551 030523; E-mail: emanolop@med.duth.gr

Date received (in revised form): 28th May 2010

\begin{abstract}
Polymorphisms in the endothelial nitric oxide synthase (eNOS) gene $(-786 T>C$ and $894 G>T)$ enhance endothelial dysfunction and have been studied in relation to coronary artery disease (CAD). In the present study, we examined the association of the above polymorphisms with CAD, as well as with myocardial infarction (MI), hypertension, diabetes and smoking in CAD patients. Study subjects consisted of 154 consecutive coronary artery bypass graft (CABG) patients and I 55 non-CAD controls. eNOS $-786 T>C$ and $894 G>T$ polymorphisms were genotyped by polymerase chain reaction-restriction fragment length polymorphism. The estimated frequencies of the $-786 \mathrm{C}$ and $894 \mathrm{~T}$ alleles did not differ between the two groups $(p=0.46$ and $p=0.84$, respectively). The prevalence of eNOS polymorphisms was not associated with MI, hypertension or diabetes in CABG patients; however, we found that the 894TT genotype and 894T allele were significantly more frequent in current/past smoker CABG patients ( 16.7 per cent and 39.6 per cent, respectively) compared with never smoker CABG patients (6.I per cent and 24.4 per cent, respectively) $(p=0.0 \mathrm{I}$ and $p<0.0 \mathrm{I}$, respectively). We found no association of eNOS $-786 C$ and $894 T$ variant alleles with CAD; however, within CABG patients, a gene-environment interaction was found between the eNOS $894 T$ allele and smoking.
\end{abstract}

Keywords: coronary artery disease, coronary artery bypass graft surgery, eNOS $-786 \mathrm{~T}>\mathrm{C}$ polymorphism, eNOS 894G > T polymorphism, smoking

\section{Introduction}

Atherosclerotic coronary artery disease (CAD) is the most common form of cardiovascular disease. CAD is a multifactorial disease of complex aetiology, influenced by both genetic and environmental determinants. ${ }^{1}$ Several risk factors for CAD have been established, such as hypertension, diabetes mellitus, lipid disorders and smoking. To comprehend fully the aetiology of CAD, special attention has been given to genetic factors. Although many candidate gene studies have been published in the past decade, the genetic background of CAD remains poorly defined. ${ }^{2}$

Numerous studies suggest that endothelial dysfunction plays a crucial role in the initiation and progression of atherosclerosis, the fundamental pathology of CAD. A key element in endothelial dysfunction is the loss of endothelium-derived nitric oxide (NO). 
NO has multiple roles in cardiovascular physiology and pathophysiology, including the regulation of vasomotor tone, cell adhesion to the endothelium, inhibition of platelet aggregation and vascular smooth muscle cell proliferation and limitation of atherogenic low-density lipoprotein oxidation. ${ }^{3}$

Endothelial nitric oxide synthase (eNOS) catalyses the biosynthesis of NO. Two functional polymorphisms have been identified in the eNOS gene: a single nucleotide polymorphism (SNP) in position 786 of the $5^{\prime}$ flanking region of the eNOS gene $(-786 T>C, \quad$ rs2070744) that reduces eNOS gene promoter activity by approximately 50 per cent ${ }^{4}$ and a $894 G>T$ polymorphism leading to amino acid substitution at position 298 (Glu298Asp, $\quad$ rs1799983), ${ }^{5}$ which results in enhanced proteolytic cleavage of the mature enzyme. These two polymorphisms are not in linkage disequilibrium, according to data derived from the HapMap database (www.hapmap.org). The dysregulation of eNOS caused by these gene polymorphisms leads to diminished NO production and is thought to contribute to the pathogenesis of several cardiovascular diseases, including myocardial infarction (MI) and CAD.

Candidates for coronary artery bypass grafting $(\mathrm{CABG})$ represent a group of patients with welldocumented and severe CAD. Selection for CABG surgery verifies the critical endpoint of severe atherosclerotic disease and constitutes a good model for its study. To the best of our knowledge, there are no data on the presence of eNOS gene polymorphisms exclusively in cohorts of CABG patients. The aim of the present study was to evaluate the association of two eNOS gene polymorphisms with $\mathrm{CAD}$ in $\mathrm{CABG}$ patients compared with non-atherosclerotic individuals. We further analysed the association of the examined polymorphisms in CABG patients with the presence of previous MI, hypertension and diabetes or smoking status.

\section{Materials and methods}

Subjects

This was a case-control study and included 309 subjects. The case group consisted of 154
Caucasian subjects of Greek origin (122 male, 32 female; mean age $68 \pm 8$ years, range $47-82$ ), who underwent CABG surgery between September 2006 and November 2008 at the Department of Cardiothoracic Surgery of the Academic General Hospital of Alexandroupolis. During the enrolment period, a total of 420 patients who were candidates for $\mathrm{CABG}$ surgery presented at the Cardiothoracic Surgery Clinic. Among them, 62 patients were excluded from the study, as they were not eligible for $\mathrm{CABG}$ surgery. From the eligible patients, 176 were either of non-Caucasian origin or their Caucasian origin could not be determined with certainty. From the remaining 182 eligible Caucasian Greek CABG patients, 28 refused to enrol and the remaining 154 patients were included in the study. The control group consisted of 155 Caucasian subjects of Greek origin (115 male, 40 female; mean age $72 \pm 9$ years, range 45-92) with no clinical evidence of CAD and also without a positive family history of CAD or MI. Forty-three of these subjects were also patients of the Cardiothoracic Surgery Department who had undergone coronary angiography for diagnostic reasons and had presented no angiographic lesions. They included individuals who had reported with chest pain but were found to be free of coronary heart disease. The remaining controls $(n=112)$ came from the Greek Health Randomized Aging Study (GHRAS), and their profiles have been described elsewhere. ${ }^{6}$ In brief, a complete medical and surgical record was obtained from each subject. All GHRAS subjects who reported absence of a diagnosed history of angina, heart failure, CAD, stroke, MI and surgeries such as CABG and angioplasty, as well as an absence of positive family history of cardiovascular disease, were classified as non-CAD controls. A representative sample of these subjects, sex matched with CABG patients, was included in the present study.

Symptomatic CAD is initially treated pharmacologically with nitrates, $\beta$-blockers and/or calciumchannel blockers. An assessment of the patient's clinical presentation, coronary anatomy, degree of inducible ischaemia on stress testing and status of ventricular function is used to determine whether 
the patient is an appropriate candidate for surgery. Inclusion criteria for all patients to undergo bypass surgery were in accordance with the American Heart association/American College of Cardiology (AHA/ ACC) guidelines for CABG surgery. ${ }^{7}$ Patients who showed CAD and ischaemic cardiomyopathy after a scintiscan that revealed a sufficient quantity of living myocardium, angina caused by coronary artery spasm (Prinzmetal) or the presence of a malignancy with a low expectation of life were not eligible for surgery and thus were not included in the study. ${ }^{7}$

Blood samples were collected from patients before the operation, as well as from healthy controls. Total serum cholesterol, high-density lipoprotein (HDL), low-density lipoprotein (LDL), triglycerides and glucose were determined by the hospital's biochemistry unit. Body mass index (BMI) was calculated as mass in kilograms divided by the square of height in metres.

Patients and controls were also evaluated for other conditions, namely hypertension, type 2 diabetes mellitus, previous MI and smoking. Subjects were defined as hypertensive if repeated blood pressure measurements were higher than 140/ $90 \mathrm{mmHg}$, or if they were on antihypertensive medications. ${ }^{8}$ Diabetes was defined as repeated measurements of fasting glucose $>126 \mathrm{mg} / \mathrm{dl}$, or if they followed anti-diabetic treatment. ${ }^{9}$ Diagnosis of MI was confirmed through patients' records based on symptoms, elevation in cardiac enzymes or electrocardiographic changes. ${ }^{7}$ According to their smoking behaviour, subjects were classified as smoking initiators or non-initiators. More specifically, individuals who continued to smoke at the time of the study, as well as those who reported having smoked at least 100 cigarettes in their lifetime and had successfully stopped smoking (ex-smokers), were defined as smoking initiators and grouped together in the current/past smokers group. Non-initiator subjects had never smoked and comprised the never smokers group. ${ }^{10}$

The study was carried out in accordance with the Declaration of Helsinki (2000) of the World Medical Association. The study protocol was approved by the Ethics Committee of the Academic General Hospital of Alexandroupolis. All participants were informed about the present study by their attending physician and gave their written consent.

\section{DNA isolation}

Approximately $3 \mathrm{ml}$ blood was collected in tubes containing ethylene diamine tetraacetic acid (EDTA). Genomic DNA was extracted from peripheral blood leucocytes by the Puregene ${ }^{\circledR}$ DNA Purification System (Gentra, Minneapolis, MN, USA), according to the manufacturer's instructions.

\section{eNOS -786T $>C$ genotyping}

A polymerase chain reaction-restriction fragment length polymorphism (PCR-RFLP) analysis was used for the identification of the $-786 \mathrm{~T}>\mathrm{C}$ polymorphism in the eNOS gene. Genomic DNA was amplified using primers described elsewhere. ${ }^{11}$ The obtained PCR product (236 base pairs [bp]) was digested with $5 \mathrm{U}$ of HapII restriction enzyme at $37^{\circ} \mathrm{C}$ overnight. The products of restriction were separated on a 2.5 per cent agarose gel and visualised by ethidium bromide staining.

\section{eNOS 894G $>T$ genotyping}

A novel PCR-RFLP protocol was designed for the analysis of the eNOS $894 G>T$ polymorphism. Genomic DNA was amplified using the following primer set: eNOSup $5^{\prime}$ ACA GCT CTG CAT TCA GCA CGG 3' (position: 1127204611272067, human genome build number 36, version 3), eNOSlow 5' GGT GTT GGG GTG TGG GAT CAG $3^{\prime}$ (position: 1127226711272288, human genome build number 36, version 3). PCR primers were designed using OLIGO-6.31 software for Windows (NBI, Plymouth, MN, USA) based on genomic DNA sequence NT_007914.14. The amplification parameters were as follows: initial 10 minutes' denaturation at $95^{\circ} \mathrm{C}, 40$ cycles with 1 minute at $95^{\circ} \mathrm{C}$, 45 seconds at $60^{\circ} \mathrm{C}$ and 55 seconds at $72^{\circ} \mathrm{C}$ and 10 minutes' final extension at $72^{\circ} \mathrm{C}$. The PCR product $(243 \mathrm{bp})$ was then digested using $5 \mathrm{U}$ of MboI restriction enzyme at $37^{\circ} \mathrm{C}$ overnight. The restriction pattern for the $894 \mathrm{G}$ allele consists of 
224 - 19 bp fragments. The $894 \mathrm{~T}$ polymorphism creates an additional restriction site and the PCR product is digested into $145-79-19 \mathrm{bp}$ fragments. The products of restriction were separated on a 2.5 per cent agarose gel and visualised by ethidium bromide staining. All PCR amplifications were carried out in a PCR-engine apparatus PTC-200 (MJ Research, Watertown, MA, USA).

Genotyping was carried out in duplicate in all samples. Additionally, 10 per cent of the samples were randomly selected and genotyped by a different investigator, who was blinded to the outcome of previous analyses. The correct genotype was confirmed in all cases.

\section{Statistical analyses}

For comparison of allelic and genotype frequencies and of categorical variables such as smoking and the incidence of hypertension and diabetes between groups, data were analysed using the chi-square test. Logistic regression analysis was used to assess the independent effect of each risk factor on the presence of CAD. One-way analysis of variance (ANOVA) was used to analyse the relationships between genotypes and the general characteristics. All continuous variables are expressed as mean \pm standard deviation and were compared using the unpaired Student's $t$ test. A $p$ value of $<0.05$ was considered significant. A post-hoc power calculation with a preset level of significance $(p=0.05)$ was performed. Multiple logistic regression analysis with a stepwise forward selection procedure was performed, with CAD as a dependent variable and the interaction of genotype with smoking in the presence of confounders (age, sex, BMI, hypertension, diabetes and LDL cholesterol) as independent variables to calculate odds ratios (ORs). The $15^{\text {th }}$ version of the Statistical Package for the Social Sciences program (SPSS) was used for the statistical analysis.

\section{Results}

\section{Characteristics of study population}

The clinical and biochemical parameters of CABG patients and controls, including standard risk factors, are shown in Table 1. CABG patients were
Table I. Clinical and biochemical characteristics of CABG patients and control subjects

\begin{tabular}{|c|c|c|c|}
\hline & $\begin{array}{l}\text { CABG } \\
\text { patients }\end{array}$ & controls & $\begin{array}{c}p \\
\text { value }\end{array}$ \\
\hline $\begin{array}{l}\text { Number of } \\
\text { subjects (n) }\end{array}$ & 154 & 155 & \\
\hline Male/female & $122 / 32$ & $115 / 40$ & ns \\
\hline Mean age (years) & $68 \pm 8$ & $72 \pm 9$ & $<0.01$ \\
\hline BMI & $28.44 \pm 3.72$ & $28.82 \pm 4.57$ & ns \\
\hline $\begin{array}{l}\text { Total cholesterol } \\
(\mathrm{mg} / \mathrm{dl})\end{array}$ & $169.97 \pm 45.78$ & $233.54 \pm 46.18$ & $<0.001$ \\
\hline $\begin{array}{l}\text { HDL-cholesterol } \\
(\mathrm{mg} / \mathrm{dl})\end{array}$ & $47.06 \pm 10.49$ & $53.32 \pm 10.29$ & $<0.001$ \\
\hline $\begin{array}{l}\text { LDL-cholesterol } \\
(\mathrm{mg} / \mathrm{dl})\end{array}$ & $94.13 \pm 37.33$ & $|52.5| \pm 40.00$ & $<0.001$ \\
\hline $\begin{array}{l}\text { Triglycerides } \\
\text { (mg/dl) }\end{array}$ & $154.96 \pm 72.79$ & $132.84 \pm 68.65$ & $<0.01$ \\
\hline Glucose (mg/dl) & $123.59 \pm 43.18$ & $113.54 \pm 32.21$ & 0.03 \\
\hline MI & $68(44.2)$ & - & \\
\hline Hypertension & $106(68.8)$ & 65 (4I.9) & $<0.001$ \\
\hline Diabetes & $63(40.9)$ & 37 (23.9) & $<0.01$ \\
\hline $\begin{array}{l}\text { Current/ } \\
\text { past-smokers }\end{array}$ & $72(46.8)$ & 65 (4I.9) & ns \\
\hline \multicolumn{4}{|c|}{$\begin{array}{l}\text { Categorical variables are presented as } n \text { (per cent) and were analysed between groups } \\
\text { using the chi-square test; all continuous variables are expressed as mean } \pm \text { standard } \\
\text { deviation and were compared using the unpaired Student's test. } \\
\text { Abbreviations: BMI, body mass index; HDL, high-density lipoprotein; LDL, low-density } \\
\text { lipoprotein; MI, myocardial infarction; NS, not significant. }\end{array}$} \\
\hline
\end{tabular}

younger $(68 \pm 8$ versus $72 \pm 9 ; p<0.01)$ and had an increased prevalence of diabetes mellitus (40.9 per cent versus 23.9 per cent; $p<0.01$ ) and hypertension (68.8 per cent versus 41.9 per cent; $p<$ 0.001) compared with control subjects. All participants included in control group were untreated subjects and thus had higher mean total cholesterol, LDL cholesterol and HDL cholesterol $(p<0.001$ for each comparison) but lower mean triglycerides $(p=0.01)$ and serum glucose $(p=0.03)$ than CABG patients. CABG patients and controls did not differ in mean BMI $(p=0.43)$ or smoking behaviour (46.8 per cent versus 41.9 per cent; $p=$ $0.39)$. 


\section{Distribution of $e N O S-786 T>C$ and $894 G>$ $T$ polymorphisms}

The frequencies of analysed eNOS genotypes and alleles between $\mathrm{CABG}$ patients and controls are shown in Table 2. The frequencies of all genotypes and alleles for both polymorphisms in the two groups were in Hardy-Weinberg equilibrium. For the eNOS $-786 T>C$ polymorphism, the frequencies of the genotypes and alleles did not differ between CABG patients and controls $(p=0.73$ and $p=0.46$, respectively). Similarly, for the $e N O S$ $894 G>T$ polymorphism, the frequencies of genotypes and alleles did not differ between the two groups $(p=0.95$ and $p=0.84$, respectively). Among all participants, 16 out of the 309 (5.2 per cent) subjects were homozygous for both the $-786 \mathrm{C}$ and the $894 \mathrm{~T}$ alleles of the eNOS gene (eNOS genotype - 786CC/894TT) and would be expected to present the lowest levels of endothelialderived NO.

When stratifying CABG patients according to the coexistence of MI, hypertension, diabetes mellitus and smoking, the $-786 \mathrm{~T}>\mathrm{C}$ polymorphism did not differ among the various categories (data not shown). For the $894 \mathrm{G}>\mathrm{T}$ polymorphism, the frequencies of the 894TT genotype and 894T allele were significantly higher in current/past smoker than never smoker CABG patients (16.7 per cent versus 6.1 per cent, $p=0.01$ and 39.6 per cent versus 24.4 per cent, $p<0.01$, respectively) (Table 3). The difference of 15.2 per cent in the frequency of the $894 \mathrm{~T}$ allele between CABG current/past smokers and never smokers had 89 per cent power at a level of statistical significance $p=0.05$. Current/past smoker and never smoker CABG patients did not differ in their clinical and biochemical parameters (Table 4). Logistic regression analysis was used to assess the association of the interaction of smoking with the G894T genotype with CAD in a model adjusted for several confounders. According to this model, independent predictors of CAD were age $(\mathrm{OR}=0.94 ; p=$ $0.003)$, BMI $(\mathrm{OR}=0.92 ; p=0.04)$, hypertension $(\mathrm{OR}=2.9 ; p=0.03)$ and LDL-cholesterol $(\mathrm{OR}=$ $0.96 ; p<0.0001)$. The parameters not associated with CAD were the interaction of smoking with
Table 2. Frequencies of eNOS $-786 T>C$ and $894 G>T$ genotypes and alleles in CABG patients and control subjects

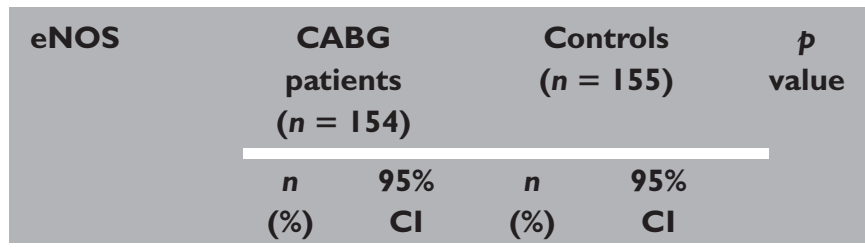

\begin{tabular}{lccccc}
$\begin{array}{l}-786 T>C \\
\text { genotypes }\end{array}$ & & & & & \\
TT & 43 & $21.3-$ & 39 & $18.8-$ & 0.73 \\
& $(27.9)$ & 35.4 & $(25.2)$ & 32.4 & \\
\hline$T C$ & 85 & $47.3-$ & 85 & $46.9-$ & \\
& $(55.2)$ & 62.9 & $(54.8)$ & 62.5 \\
CC & 26 & $11.6-$ & 31 & $14.3-$ & \\
& $(16.9)$ & 23.4 & $(20.0)$ & 26.8 \\
$-786 T>C$ & $n=308$ & $n=310$ & \\
alleles & & & & & \\
$T$ & 171 & $49.9-$ & 163 & $47.0-$ \\
$T$ & $(55.5)$ & 61.0 & $(52.6)$ & 58.1 & \\
& 137 & $39.0-$ & 147 & $41.9-$ & \\
C & $(44.5)$ & 50.1 & $(47.4)$ & 52.9
\end{tabular}

$894 G>T$

genotypes

$\begin{array}{cccccc}G G & 74 & 40.3- & 72 & 38.7- & 0.95 \\ & (48.1) & 55.9 & (46.5) & 54.3 & \\ \text { GT } & 63 & 33.4- & 66 & 34.9- & \\ & (40.9) & 48.8 & (42.5) & 50.4 \\ T T & 17 & 6.8- & 17 & 6.8- \\ & (11.0) & 16.7 & (11.0) & 16.6\end{array}$

$\begin{array}{lccccc}\begin{array}{l}894 G>T \\ \text { alleles }\end{array} & n=308 & n=310 & \\ \text { G } & 211 & 63.2- & 210 & 62.4- & 0.84 \\ & (68.5) & 73.5 & (67.7) & 72.8 & \\ T & 97 & 26.5- & 100 & 27.2- & \\ & (31.5) & 36.8 & (32.3) & 37.6\end{array}$

Frequencies of all genotypes and alleles are in Hardy-Weinberg equilibrium. Genotype and allele frequencies between the two groups were analysed by the chi-square test.

Abbreviations: $\mathrm{CABG}$, coronary artery bypass graft; $\mathrm{Cl}$, confidence interval.

the G894T genotype $(p=0.92)$, sex $(p=0.36)$ and diabetes $(p=0.32)$. There was no difference in the other examined subgroups (MI, hypertension, type 2 diabetes) among genotypes or alleles for the 
Table 3. Frequencies of the eNOS $894 G>T$ genotypes and alleles in CABG patients according to their smoking behaviour

\begin{tabular}{|c|c|c|c|c|}
\hline \multirow[b]{2}{*}{$\begin{array}{l}\text { eNOS } \\
894 G>T \\
\text { genotypes }\end{array}$} & \multicolumn{2}{|c|}{$\begin{array}{l}\text { CABG current/ } \\
\text { past smokers } \\
(n=72)\end{array}$} & \multicolumn{2}{|c|}{$\begin{array}{l}\text { CABG never } \\
\text { smokers } \\
(n=82)\end{array}$} \\
\hline & $n(\%)$ & $\begin{array}{l}95 \% \\
\mathrm{Cl}\end{array}$ & $n(\%)$ & $\begin{array}{l}95 \% \\
\mathrm{Cl}\end{array}$ \\
\hline GG & $\begin{array}{c}27 \\
(37.5)\end{array}$ & $\begin{array}{l}26.9- \\
49.0\end{array}$ & $\begin{array}{c}47 \\
(57.3)\end{array}$ & $\begin{array}{l}46.5- \\
67.6\end{array}$ \\
\hline GT & $\begin{array}{c}33 \\
(45.8)\end{array}$ & $\begin{array}{l}34.7- \\
57.3\end{array}$ & $\begin{array}{c}30 \\
(36.6)\end{array}$ & $\begin{array}{l}26.8- \\
47.3\end{array}$ \\
\hline$T T$ & $\begin{array}{c}12 \\
(16.7)\end{array}$ & $\begin{array}{l}9.5- \\
26.5\end{array}$ & $\begin{array}{c}5 \\
(6.1)\end{array}$ & $\begin{array}{l}2.4- \\
12.9\end{array}$ \\
\hline$p$ value & \multicolumn{4}{|c|}{$0.02 * / 0.01 * *$} \\
\hline Alleles & \multicolumn{2}{|c|}{$n=144$} & \multicolumn{2}{|c|}{$n=164$} \\
\hline$G$ & $\begin{array}{c}87 \\
(60.4)\end{array}$ & $\begin{array}{l}52.3- \\
68.1\end{array}$ & $\begin{array}{c}124 \\
(75.6)\end{array}$ & $\begin{array}{l}68.6- \\
81.7\end{array}$ \\
\hline$T$ & $\begin{array}{c}57 \\
(39.6)\end{array}$ & $\begin{array}{l}31.9- \\
47.7\end{array}$ & $\begin{array}{c}40 \\
(24.4)\end{array}$ & $\begin{array}{l}18.3- \\
31.4\end{array}$ \\
\hline$p$ value & \multicolumn{4}{|c|}{$<0.01$} \\
\hline $\begin{array}{c}{ }^{*} p \text { value }=0.02 \\
\text { smoker and } n \\
* \text { * } p \text { value }=0.01 \\
\text { past smoker a } \\
\text { Genotype and a } \\
\text { chi-square tes } \\
\text { Abbreviations: }\end{array}$ & $\begin{array}{l}\text { parison ar } \\
\text { oker CAB } \\
\text { nparison } \\
\text { r smoker } \\
\text { quencies b } \\
\text { oronary a }\end{array}$ & $\begin{array}{l}\text { I eNOS } 89 \\
\text { ents. } \\
\text { n eNOS } 89 \\
\text { patients. } \\
\text { the two } \\
\text { ypass graft }\end{array}$ & $\begin{array}{l}\text { genotype } \\
\text { id TT geno } \\
\text { were analy } \\
\text { infidence ir }\end{array}$ & $\begin{array}{l}\text { rent/past } \\
\text { n current/ } \\
\text { ng the }\end{array}$ \\
\hline
\end{tabular}

$894 G>T$ polymorphism (data not shown). The same analysis in the non-CAD control group showed no interaction between the studied polymorphisms with hypertension, diabetes or smoking (data not shown).

\section{Discussion}

Candidates for CABG represent a group of patients with well-documented and severe CAD. Selection for $C A B G$ surgery verifies the critical endpoint of severe atherosclerotic disease and constitutes a good model for its study. Few genetic association studies have examined CABG patients as a separate, clinically defined model of severe atherosclerosis. In these patients, we investigated the association of $-786 \mathrm{~T}>\mathrm{C}$ and $894 \mathrm{G}>\mathrm{T}$ polymorphisms of the
eNOS gene with CAD. Our results show that eNOS $-786 \mathrm{C}$ and $894 \mathrm{~T}$ variants are not independent predisposing factors for severe CAD. We found, however, an interaction between the 894T allele and smoking in CABG patients. This genesmoking interaction supports the idea that smoking enhanced endothelial damage in the presence of specific gene variants, such as 894T, of the eNOS gene in our study.

Several studies have investigated the possible association of eNOS gene polymorphisms with CAD, with conflicting results. Similar to our results, some studies have reported a lack of association of $e N O S-786 T>C$ and $894 G>T$ polymorphisms with CAD in other populations of Caucasian or Asian origin. ${ }^{11-16}$ There have, however, been a few studies showing a positive association of eNOS gene polymorphisms with CAD. ${ }^{17,18}$ Two meta-analyses conducted by Casas et al. showed that the eNOS $-786 \mathrm{C}$ allele is associated with slightly increased risk for $\mathrm{CAD}^{19}$ and that homozygosity for the 894 Tallele is associated with a moderately increased risk for ischaemic heart disease. ${ }^{20}$ Both studies, however, noted the substantial heterogeneity of included studies, and in the last updated meta-analysis they highlighted that they observed statistical evidence of small-study bias in studies of the G894T and $-786 \mathrm{~T}>\mathrm{C}$ polymorphisms. ${ }^{19}$ Our approach was to use a patient population with well-documented, severe atherosclerotic disease, assessed by experienced clinicians.

It has been suggested that interaction of eNOS gene polymorphisms with environmental factors such as smoking may influence the late stages of CAD and also alter the early pathogenesis of atherosclerosis by modulation of endothelial function. ${ }^{21}$ In the present study, we found that the eNOS $894 \mathrm{~T}$ allele had a higher prevalence in current/past smoker than never smoker CABG patients. Smoking induces oxidative stress, thereby suppressing eNOS activity, and also increases peroxynitrate formation, causing a further suppression of eNOS activity, because peroxynitrate inhibits eNOS production. $^{22}$ It also changes the function of eNOS, from catalysing the synthesis of $\mathrm{NO}$ to catalysing the synthesis of oxygen radicals, finally it decreases 
Table 4. Clinical and biochemical characteristics of CABG patients according to their smoking behaviour

\begin{tabular}{|c|c|c|c|}
\hline & $\begin{array}{c}\text { CABG } \\
\text { current/past } \\
\text { smokers }\end{array}$ & $\begin{array}{c}\text { CABG never } \\
\text { smokers }\end{array}$ & $\begin{array}{c}p \\
\text { value }\end{array}$ \\
\hline $\begin{array}{l}\text { Number of } \\
\text { subjects (n) }\end{array}$ & 72 & 82 & \\
\hline Male/female & $66 / 6$ & $56 / 26$ & $<0.001$ \\
\hline Mean age (years) & $71 \pm 9$ & $82 \pm 7$ & $<0.001$ \\
\hline BMI & $28.00 \pm 3.68$ & $28.82 \pm 3.73$ & ns \\
\hline $\begin{array}{l}\text { Total cholesterol } \\
(\mathrm{mg} / \mathrm{dl})\end{array}$ & $167.42 \pm 46.86$ & $|72.3| \pm 44.98$ & ns \\
\hline $\begin{array}{l}\text { HDL-cholesterol } \\
(\mathrm{mg} / \mathrm{dl})\end{array}$ & $45.59 \pm 11.00$ & $48.02 \pm 9.62$ & ns \\
\hline $\begin{array}{l}\text { LDL-cholesterol } \\
(\mathrm{mg} / \mathrm{dl})\end{array}$ & $93.35 \pm 35.48$ & $94.78 \pm 39.04$ & ns \\
\hline $\begin{array}{l}\text { Triglycerides } \\
\text { (mg/dl) }\end{array}$ & $166.33 \pm 76.45$ & $|44.99 \pm 68.4|$ & ns \\
\hline Glucose $(\mathrm{mg} / \mathrm{dl})$ & $125.80 \pm 45.49$ & $121.61 \pm 41.22$ & ns \\
\hline MI & $34(47.2)$ & $34(4 I .5)$ & ns \\
\hline Hypertension & $46(63.9)$ & $60(73.2)$ & ns \\
\hline Diabetes & $27(37.5)$ & $36(43.9)$ & ns \\
\hline
\end{tabular}

pteridine-tetrahydrobiopterin levels, causing the uncoupling of eNOS. ${ }^{3}$ Since both polymorphisms in the eNOS gene cause loss of function and a reduction in eNOS enzymatic activity, NO levels in subjects carrying these polymorphisms are even lower, resulting in further endothelial damage. The interaction of smoking with the G894T polymorphism was present solely in CABG patients. A possible explanation for this finding derives from a recent demonstration that there is a relationship between endothelial dysfunction and increased Rho kinase (ROCK) activity in smokers and that the activation of ROCK contributes to the reduced NO bioavailability in humans with atherosclerosis via eNOS suppression. ${ }^{23,24}$ Thus, the interaction we found between the eNOS $894 \mathrm{~T}$ allele and smoking in CABG patients might also be mediated through ROCK activation. Despite the number of studies examining the association between eNOS gene polymorphisms and CAD, there are only a few reports on their interaction with pro-atherogenic risk factors such as smoking. For the $894 \mathrm{~T}$ allele, it has been shown that carriage of this allele increases the likelihood of smoking-associated endothelial dysfunction ${ }^{21}$ and of angiographically proven $\mathrm{CAD},{ }^{25}$ a result which is in agreement with our finding of a higher frequency of the $894 \mathrm{~T}$ allele in current/past smoker than never smoker CABG patients.

Our study has certain limitations. CABG patients and non-CAD controls were matched for sex but significantly differed in age, lipid profile and incidence of hypertension and diabetes. Firstly, CABG patients were younger than non-CAD controls. 
This is a welcome difference, however, since it indicates that control subjects have been disease-free for a longer time and, presumably, the possibility of them developing CAD complications in the future is reduced. Differences in lipid profile could possibly be attributed to the fact that most CABG patients were receiving medications (mostly statins) which affect lipid profile, while most control subjects did not receive any such drugs. Finally, the incidence of hypertension and diabetes was lower in non-CAD controls, as it was not possible to find enough subjects with this condition among our control population, CAD being the main complication of these pathological conditions. We found no association between any of the studied polymorphisms and diabetes or hypertension in the analysis performed in all subjects, however (data not shown).

In conclusion, we studied two polymorphisms in the eNOS gene in Greek CABG patients, which have both been subject to controversy concerning their relevance to CAD. Our results show that in this patient population, the $-786 \mathrm{C}$ and $894 \mathrm{~T}$ alleles of the eNOS gene are not associated with CAD. The eNOS $894 G>T$ polymorphism is associated with $\mathrm{CAD}$ in current/past smoker patients, however; a finding which suggests that this polymorphism may be associated with differences in the response of the endothelium to smoking status.

\section{Acknowledgments}

Georgia Ragia is a recipient of a predoctoral fellowship from the Greek State Scholarships Foundation (IKY).

\section{References}

1. Nanni, L., Romualdi, C., Maseri, A. and Lanfranchi, G. (2006), 'Differential gene expression profiling in genetic and multifactorial cardiovascular diseases', J. Mol. Cell. Cardiol. Vol. 41, pp. 934-948.

2. Lanktree, M., Oh, J. and Hegele, R.A. (2008), 'Genetic testing for atherosclerosis risk: Inevitability or pipe dream?', Can. J. Cardiol. Vol. 24, pp. 851-854.

3. Schulz, E., Jansen, T., Wenzel, P., Daiber, A. et al. (2008), 'Nitric oxide, tetrahydrobiopterin, oxidative stress, and endothelial dysfunction in hypertension', Antioxid. Redox. Signal. Vol. 10, pp. 1115-1126.

4. Nakayama, M., Yasue, H., Yoshimura, M., Shimasaki, Y. et al. (1999), 'T-786- $>$ C mutation in the $5^{\prime}$-flanking region of the endothelial nitric oxide synthase gene is associated with coronary spasm', Circulation Vol. 99 , pp. $2864-2870$
5. Yoshimura, M., Yasue, H., Nakayama, M., Shimasaki, Y. et al. (1998), 'A missense Glu298Asp variant in the endothelial nitric oxide synthase gene is associated with coronary spasm in the Japanese', Hum. Genet. Vol. 103, pp. $65-69$.

6. Kanoni, S. and Dedoussis, G.V. (2008), 'Design and descriptive characteristics of the GHRAS: The Greek Health Randomized Aging Study', Med. Sci. Monit. Vol. 14, pp. CR204-212.

7. Eagle, K.A., Guyton, R.A., Davidoff, R., Edwards, F.H. et al. (2004), "ACC/AHA 2004 guideline update for coronary artery bypass graft surgery: Summary article. A report of the American College of Cardiology/American Heart Association Task Force on Practice Guidelines (Committee to Update the 1999 Guidelines for Coronary Artery Bypass Graft Surgery)', J. Am. Coll. Cardiol. Vol. 44, pp. e213-310.

8. Mansia, G., De Backer, G., Dominiczak, A., Cifkova, R. et al. (2007), '2007 ESH-ESC Guidelines for the management of arterial hypertension: The task force for the management of arterial hypertension of the European Society of Hypertension (ESH) and of the European Society of Cardiology (ESC)', Blood Press. Vol. 16, pp. 135-232.

9. IDF Clinical Guidelines Task Force (2006), 'Global Guideline for Type 2 Diabetes: Recommendations for standard, comprehensive, and minimal care', Diabet. Med. Vol. 23, pp. 579-593.

10. Iordanidou, M., Tavridou, A., Petridis, I., Kyroglou, S. et al. (2010), 'Association of polymorphisms of the serotonergic system with smoking initiation in Caucasians', Drug Alcohol Depend. Vol. 108, pp. $70-76$.

11. Kim, I.J., Bae, J., Lim, S.W., Cha, D.H. et al. (2007), 'Influence of endothelial nitric oxide synthase gene polymorphisms $(-786 \mathrm{~T}>\mathrm{C}, 4 \mathrm{a} 4 \mathrm{~b}$, $894 \mathrm{G}>\mathrm{T}$ ) in Korean patients with coronary artery disease', Thromb. Res. Vol. 119, pp. 579-585.

12. Jeerooburkhan, N., Jones, L.C., Bujac, S., Cooper, J.A. et al. (2001), 'Genetic and environmental determinants of plasma nitrogen oxides and risk of ischemic heart disease', Hypertension Vol. 38, pp. 1054-1061.

13. Guzik, T.J., Black, E., West, N.E., McDonald, D. et al. (2001), 'Relationship between the G894T polymorphism (Glu298Asp variant) in endothelial nitric oxide synthase and nitric oxide-mediated endothelial function in human atherosclerosis', Am. J. Med. Genet. Vol. 100, pp. $130-137$.

14. Poirier, O., Mao, C., Mallet, C., Nicaud, V. et al. (1999), 'Polymorphisms of the endothelial nitric oxide synthase gene: No consistent association with myocardial infarction in the ECTIM study', Eur. J. Clin. Invest. Vol. 29, pp. 284-290.

15. Granath, B., Taylor, R.R., van Bockxmeer, F.M. and Mamotte, C.D. (2001), 'Lack of evidence for association between endothelial nitric oxide synthase gene polymorphisms and coronary artery disease in the Australian Caucasian population', J. Cardiovasc. Risk Vol. 8, pp. $235-241$

16. Afrasyap, L. and Ozturk, G. (2004), 'NO level and endothelial NO synthase gene polymorphism (Glu298Asp) in the patients with coronary artery disease from the Turkish population', Acta Biochim. Biophys. Sin. (Shanghai) Vol. 36, pp. 661-666.

17. Colombo, M.G., Paradossi, U., Andreassi, M.G., Botto, N. et al. (2003), 'Endothelial nitric oxide synthase gene polymorphisms and risk of coronary artery disease', Clin. Chem. Vol. 49, pp. 389-395.

18. Tangurek, B., Ozer, N., Sayar, N., Terzi, S. et al. (2006), 'The relationship between endothelial nitric oxide synthase gene polymorphism (T-786 C) and coronary artery disease in the Turkish population', Heart Vessels Vol. 21, pp. 285-290.

19. Casas, J.P., Cavalleri, G.L., Bautista, L.E., Smeeth, L. et al. (2006), 'Endothelial nitric oxide synthase gene polymorphisms and cardiovascular disease: A HuGE review', Am. J. Epidemiol. Vol. 164, pp. 921-935.

20. Casas, J.P., Bautista, L.E., Humphries, S.E. and Hingorani, A.D. (2004), 'Endothelial nitric oxide synthase genotype and ischemic heart disease: Meta-analysis of 26 studies involving 23028 subjects', Circulation Vol. 109, pp. $1359-1365$.

21. Leeson, C.P., Hingorani, A.D., Mullen, M.J., Jeerooburkhan, N. et al. (2002), 'Glu298Asp endothelial nitric oxide synthase gene polymorphism 
interacts with environmental and dietary factors to influence endothelial function', Circ. Res. Vol. 90, pp. 1153-1158.

22. Sarkar, R., Gelabert, H.A., Mohiuddin, K.R., Thakor, D.K. et al. (1999), 'Effect of cigarette smoke on endothelial regeneration in vivo and nitric oxide levels', J. Surg. Res. Vol. 82, pp. 43-47.

23. Nohria, A., Grunert, M.E., Rikitake, Y., Noma, K. et al. (2006), 'Rho kinase inhibition improves endothelial function in human subjects with coronary artery disease', Circ. Res. Vol. 99, pp. 1426-1432.
24. Noma, K., Goto, C., Nishioka, K., Hara, K. et al. (2005), 'Smoking, endothelial function, and Rho-kinase in humans', Arterioscler. Thromb. Vasc. Biol. Vol. 25, pp. 2630-2635.

25. Rios, D.L., D’Onofrio, L.O., Souza, J.K., Queiroz, A.M. et al. (2007), 'Smoking-dependent and haplotype-specific effects of endothelial nitric oxide synthase gene polymorphisms on angiographically assessed coronary artery disease in Caucasian- and African-Brazilians', Atherosclerosis Vol. 193, pp. 135-141. 